\title{
EXPERIENCE OF ANGER IN PATIENTS WITH IRRITABLE BOWEL SYNDROME IN ROMANIA
}

\author{
MIHAELA FADGYAS STĂNCULETE ${ }^{1}$, CRISTINA POJOGA ${ }^{2,3}$, \\ DAN LUCIAN DUMITRAȘCU ${ }^{4}$
}

\author{
${ }^{1}$ Department of Neurosciences, Iuliu Hatieganu University of Medicine and \\ Pharmacy, Cluj-Napoca, Romania \\ ${ }^{2}$ Prof Dr Octavian Fodor Regional Institute of Gastroenterology and Hepatology, \\ Cluj-Napoca, Romania \\ ${ }^{3}$ Department of Clinical Psychology and Psychotherapy, Babes-Bolyai University, \\ Cluj-Napoca, Romania \\ ${ }^{4} 2^{\text {nd }}$ Department of Internal Medicine, Iuliu Hatieganu University of Medicine and \\ Pharmacy, Cluj-Napoca, Romania
}

\section{Abstract}

Background and aims. Anger is strongly associated with the coping style, personality, interpersonal conflicts and quality of life. Increased research is being focused on the negative impact of anger on irritable bowel syndrome (IBS). Certain psychological areas such as anger have not been investigated in Romanian patients. The present study aims to determine the basal differences in experiencing anger between IBS patients and controls.

Method. We examined the State-Trait anger in 60 subjects with IBS and 45 controls. The socio-demographic data and the State-Trait Anger Inventory were administered in individual sessions.

Results evidenced that the IBS group had high mean scores for trait anger. No significant differences between the groups were detected on state anger.

Conclusion. Higher levels of trait anger characterize IBS patients when compared to controls and this may be associated with symptoms. These findings are discussed within the context of other data suggesting that trait anger contributes to development and evolution of IBS, perhaps through modulation of the colonic motor activity.

Keywords: anger, irritable bowel syndrome, brain-gut axis.

\section{Background and aims}

Irritable bowel syndrome (IBS) is a chronic disorder with great impact in every day functioning. Its etiology and pathogenesis are still incompletely understood, but the research over the past several years has led to progress in the understanding of IBS.

The etiology of this syndrome has been attributed to altered gastrointestinal motility, visceral hypersensitivity, and psychosocial factors, but most of all to the disturbance of the brain-gut axis [1]. A number of studies have suggested that stress can lead to IBS exacerbations $[2,3,4]$. One pathway of such influences could involve direct effects of anger on relevant physiological mechanism [5]. Anger is

Manuscript received: 24.04.2014

Accepted: 12.05.2014

Address for correspondence: mihaela.fadgyas@umfcluj.ro an emotional state widely spread in the general population. Spielberger defined anger as "psychological state and trait consisting of subject's feelings that vary in intensity and frequency from mild irritation to intense fury and would fluctuate overtime as a function of frustration, perceived insults or being verbally or physically attacked by others, experienced overtime; it is accompanied by arousal of autonomic, nervous and neuro-endocrine process" [6]. Relatively little is known about the mechanisms by which psychosocial factors, such as general anger proneness (trait anger) and anger expression style, may be associated with pro-inflammatory processes and visceral hypersensitivity that contribute to IBS signs and symptoms $[7,8,9]$. Studies have generally found that a network of interconnected brain regions including the orbito-frontal cortex, rostral anterior cingulate cortex, amygdala, anterior insula and 
periaqueductal grey underlies regulation of both pain and anger [10].

Previous studies documented a relationship between the tendency to control or repress anger, the level of abdominal pain and augmented postprandial colonic motility $[11,12]$. Other authors found that antral motor activity decreased in IBS patients and increased in controls [5]. In regard to anger, the aforementioned results suggest that negative emotions could have significant impact on IBS symptomatology.

Current studies investigated if patients with IBS were more prone to anger and reported more suppressed anger in daily life than control healthy subjects.

\section{Patients and methods}

Upon the approval of the Ethics in Research Committee, patients between 18 and 70 years old fulfilling the Rome III IBS criteria were included in the study. IBS was diagnosed by gastroenterologists through conventional procedures. Colonoscopy is not needed to make a diagnosis of IBS but was performed to rule out other diseases of gastrointestinal tract. The IBS group included 40 females and 20 males, mean age 47.17 years $(S D=15.90)$. The healthy controls group included 24 females and 21 males with a mean age of $47.42(\mathrm{SD}=10.23)$.

Socio-demographic data were collected before presenting The State Trait Anger Expression Inventory second edition (STAXI-2, Spielberger, 1999) - Romanian version (Pitariu and Iliescu, 2006) [13]. This test consists of three parts: State-Anger (items 1 to 15), Trait-Anger (items 16 to 25), and Anger Expression (items 26 to 57). The STAXI-2 is a 57 item scale which uses 4-points Likert scales. It consists of six scales, and five subscales and an anger expression index. The six scales are State Anger (S-Ang), Trait Anger (T-Ang), Anger Expression-Out (AX-O), Anger Expression-In (AX-I), Anger Control-Out (AC-O), and Anger Control-In (AC-I). The five sub scales are State Anger/feeling, State Anger/verbal, State Anger/ physical, Trait Anger/Temperament, Trait Anger/Reaction Index.

The S-Ang measures how intensely a person experiences anger during a period specified by the examiner. The Likert scale for the State Anger scale ranges from 1 (not at all) to 4 (very much so).

The T-Ang scale measures an individual's proneness to experience angry feelings. The Likert scale for Trait anger ranges from 1 (almost never) to 4 (almost always).

The AX-O, AX-I, AC-O, AC-I scales measure the modalities in which a person expresses and controls anger. The Likert scale ranges from 1(almost never) to 4 (almost always).

STAXI 2 has been used to measure anger in relation with physical health. It has good concurrent validity and internal consistency reliability. For the state anger scale, scores could range from 15 to 60 , while for feeling angry (S-Ang/F), feel like expressing anger verbally (S-Ang/V), and feel like expressing anger physically (S-Ang/P), scores could range from 5-20. For trait anger, scores could range from 10 to 40. For angry temperament (T-Ang/T) and angry reaction (T-Ang/R) scores could range from 4 to 16 . For anger expression-in, anger expression-out, anger controlin, and anger control-out scores could range from 8 to 32 . The AX Index provides a global estimate of the person's tendencies to express anger either toward other people, or toward her/himself. It is based on the person's responses to the AX-O, AX-I, AC-O, and AC-I items. Scores could range between 0 and 96 .

Differences among the groups were investigated by independent t-samples analysis. Group categories were used as independent variables while the STAXI-2 measures served as dependent variables. The significance level for the test was $p<0.05$. The statistical analysis was performed with Statistical Package for the Social Sciences- SPSS for Windows software (IBM Corp., Armonk, USA)- version 16.0.

Table I. shows the descriptive statistical analyses and STAXI-2 mean scores in IBS patients and healthy controls

\begin{tabular}{|c|c|c|c|c|c|c|}
\hline & \multicolumn{2}{|c|}{ IBS patients } & \multicolumn{2}{|c|}{ Healthy controls } & \multicolumn{2}{|c|}{ Independent samples test } \\
\hline & Mean & SD & Mean & SD & $\mathrm{F}$ & $\mathrm{p}$ \\
\hline S-Ang & 17.95 & 7.46 & 17.04 & 6.72 & .002 & .964 \\
\hline S-Ang/F & 6.92 & 3.18 & 5.98 & 2.57 & .498 & .482 \\
\hline S-Ang/V & 5.81 & 2.77 & 5.57 & 2.13 & .546 & .462 \\
\hline S-Ang/P & 5.22 & 1.96 & 5.48 & 2.39 & .765 & .384 \\
\hline T-Ang & 19.56 & 7.54 & 17.88 & 5.56 & 4.216 & $.043^{*}$ \\
\hline T-Ang/T & 8.10 & 3.74 & 6.77 & 2.71 & 3.84 & .053 \\
\hline T-Ang/R & 8.71 & 3.25 & 8.06 & 2.70 & 2.683 & .104 \\
\hline $\mathrm{AX}-\mathrm{O}$ & 15.65 & 5.53 & 15.02 & 4.12 & 3.685 & .058 \\
\hline AX-I & 16.86 & 5.57 & 15.46 & 4.08 & 1.147 & .287 \\
\hline $\mathrm{AC}-\mathrm{O}$ & 20.06 & 6.49 & 20.64 & 5.58 & 1.105 & .296 \\
\hline AC-I & 20.95 & 6.73 & 21.80 & 5.43 & 3.022 & .085 \\
\hline AX-index & 39.50 & 14.96 & 36.04 & 11.22 & 6.14 & $.015^{*}$ \\
\hline
\end{tabular}




\section{Results}

Regarding socio-demographic features no significant differences between IBS patients and controls were documented.

Means scores are within the normal range for both groups.

Significant differences between groups were documented regarding the variable T-Ang $(\mathrm{p}=0.043)$ and AX Index $(\mathrm{p}=0.015)$, all higher in IBS patients group.

\section{Discussion}

This study is the first to our knowledge that aims to describe anger in a sample of Romanian IBS patients. The patients' state anger levels were not significantly different from the control group. State anger refers to how intensely subjects experiences anger during a specified situation. Our findings agree with those by Zocalli at al who investigated the experience and the expression of anger and the prevalent ego-defense mechanisms in a group of non-psychiatric patients with irritable bowel syndrome [14].

However, our study revealed significant differences between IBS patients and controls on trait anger, suggesting that anger may play a role in IBS symptoms. Trait anger represents a stable dispositional feature and includes a general predisposition to become angry. Patients with IBS are more prone to be angrier than healthy controls. From this point of view, patients with IBS resemble those with other functional pain disorders in whom a general predisposition to anger has been shown $[14,15]$.

Our results suggesting the predisposition of IBS patients to experience angry feelings support the general hypothesis that patients with IBS present high levels of anger on Trait anger scale and AX index. This finding is consistent with the study that shows that the levels of trait anger were higher in IBS patients (even when other psychological characteristics were controlled) than in patients with organic bowel disease [9].

In a study by Muscatello et al. involving 42 patients with constipation-predominant IBS (C-IBS) and 44 diarrhea-predominant IBS (D-IBS) although STAXI 2 mean scores for both groups were within normal range, C-IBS patients scored higher on State-anger scale and subscales and on Trait-anger/Angry reaction scale [11].

The mechanism and process by which anger influences gut motility is yet to be clarified. According to a study conducted by Blomhoff et al. in 2000, it has been suggested that gut motility could be considered an indicator of the level of stress and intensity of the subject's affective involvement [16]. Imaging studies reported that IBS patients showed activation in brain regions with a role in endogenous pain modulation [17]. It has been suggested that symptoms related to anger may activate pain facilitating mechanism and compromise pain inhibitory mechanism [18].
Our findings suggests that predisposition to anger contributes to development and evolution of IBS, perhaps through modulation of colonic motor activity but the crosssectional design cannot confirm causal relationships. The tendency to become angry has potential implication in evaluation and treatment of IBS patients.

Our study has some limitations that may affect the interpretation of results. The IBS patients were selected from the treatment-seeking patients referred to gastroenterology clinics and the study patients may not be fully representative of IBS patients in general population. Also, our sample size was moderately small.

\section{Conclusions}

IBS patients had significantly higher levels of trait anger than healthy subjects. The findings emphasize the importance of taking anger into account when assessing IBS patients. Further studies in this area should continue to examine the influence of anger on IBS symptoms and physiological reactivity.

\section{References}

1. Mayer EA. Gut feelings: the emerging biology of gut-brain communication. Nature Rev Neurosci. 2011;12(8):453-466.

2. O'Malley D, Quigley EM, Dinan TG, Cryan JF. Do interactions between stress and immune responses lead to symptom exacerbations in irritable bowel syndrome? Brain Behav Immun. 2011;25(7):1333-1341.

3. Konturek PC, Brzozowski T, Konturek SJ. Stress and the gut: pathophysiology, clinical consequences, diagnostic approach and treatment options. J Physiol Pharmacol. 2011;62(6):591-599.

4. Cryan JF, Dinan TG. Mind-altering microorganisms: the impact of the gut microbiota on brain and behaviour. Nat Rev Neurosc. 2012;13(10):701-712.

5. Welgan P, Meshkinpour H, Ma L. Role of anger in antral motor activity in irritable bowel syndrome. Dig Dis Sci. 2000;45(2):248251.

6. Spielberger CD. Manual for the State-Trait Anger Expression Inventory-2. Odessa, FL: Psychological Assessment Resources; 1999.

7. Elsenbruch S. Abdominal pain in Irritable Bowel Syndrome: a review of putative psychological, neural and neuro-immune mechanisms. Brain Behav Immun. 2011;25(3):386-394.

8. Surdea-Blaga T, Băban A, Dumitrascu DL. Psychosocial determinants of irritable bowel syndrome. World J Gastroenterol. 2012;18(7):616-326.

9. Beesley H, Rhodes J, Salmon P. Anger and childhood sexual abuse are independently associated with irritable bowel syndrome. Br J Health Psychol. 2010;15(Pt 2):389-399.

10. Bruehl S, Burns JW, Chung OY, Chont M. Pain-related effects of trait anger expression: neural substrates and the role of endogenous opioid mechanisms. Neurosci Biobehav Rev. 2009;33(3):475-491.

11. Muscatello MR, Bruno A, Pandolfo G, Micò U, Stilo S, Scaffidi M, et al. Depression, anxiety and anger in subtypes of irritable bowel syndrome patients. J Clin Psychol Med Settings. 2010;17(1):64-70. 
12. Taché Y, Mönnikes H, Bonaz B, Rivier J. Role of CRF in stress-related alterations of gastric and colonic motor function. Ann N Y Acad Sci. 1993;697:233-243.

13. Spielberger C. State -Trait Anger Expression Inventory; Romanian version Horia Pitariu, Dragos Iliescu. Cluj-Napoca: Odyseea, 2006.

14. Zoccali R, Muscatello MRA, Bruno A, Barillà G, Campolo $\mathrm{D}$, Meduri M, et al. Anger and ego-defence mechanisms in nonpsychiatric patients with irritable bowel syndrome. Dig Liv Dis. 2006;38:195-201.

15. Fives CJ, Kong G, Fuller JR, DiGiuseppe R. Anger, aggression, and irrational beliefs in adolescents. Cognit Therapy Res. 2011;35(3):199-208.
16. Blomhoff S, Spetalen S Jacobsen MB, Vatn M, Malt UF. Intestinal reactivity to words with emotional content and brain information processing in irritable bowel syndrome. Dig Dis Sci. 2000;45(6):1160-1165.

17. Labus JS, Naliboff BN, Fallon J, Berman SM, Suyenobu B, Bueller JA, et al. Sex differences in brain activity during aversive visceral stimulation and its expectation in patients with chronic abdominal pain: a network analysis. Neuroimage. 2008;41(3):1032-1043.

18. Mayer EA, Berman S, Suyenobu B, Labus J, Mandelkern MA, Naliboff BD, et al. Differences in brain responses to visceral pain between patients with irritable bowel syndrome and ulcerative colitis. Pain. 2005;115(3):398-409. 